\title{
Coastal Storms of the Eastern United States
}

\author{
John R. Mather, ${ }^{1}$ Henry Adams, III, and Gary A. Yoshtoka \\ Laboratory of Climatology, C.W. Thornthwaite Associates, Elmer, N.J.
}

(Manuscript received 15 April 1964, in revised form 17 June 1964)

\begin{abstract}
Storms resulting in damage to the East Coast of the United States over the past 42 years have been classified into eight different synoptic situations: hurricanes; wave developments well east of the southeast coast or in the vicinity of Cuba; wave developments over Florida or the nearby Atlantic coastal waters; wave developments in the Gulf of Mexico west of $85 \mathrm{~W}$ longitude; inland depressions that deepen upon reaching the coast; secondary cyclonic disturbances in the Hatteras area; intense cyclones moving northeastward, west of the coast; and strong cold fronts with associated squall lines. The seasonal and geographical distributions of these storm types are investigated. Coastal storms of moderate to severe intensity might be expected at any place along the East Coast of the United States on an average of once every 1.4 years in New York and New Jersey, the area of most frequent occurrence, to once every 4.2 years in Georgia, the area of least frequent occurrence.
\end{abstract}

\section{Introduction}

During the period 5-9 March 1962, a severe, slow-moving coastal storm brought approximately $\$ 200,000,000$ worth of damage to the eastern seaboard of the United States over a four-day period. Government agencies, local groups and private organizations were all spurred into action in an effort to rebuild the devastated area and to produce sound plans for the future development of the exposed coastal margins. Studies of how to rebuild and protect the coasts themselves, as well as basic investigations of the patterns of coastal occupancy and development, perception of coastal environments and hazards, possible zoning and development ordinances, and the frequency and nature of storms producing coastal damage, were all begun or extended. ${ }^{2}$ The present report sums up the result of an investigation of storms affecting the East Coast of the United States during the 42-year period, 1921-1962. This study has sought to summarize the frequency of storms that have produced significant water damage along the coastal margin and to identify the general types of weather conditions that result in such damage. From a basic knowledge of the climatology of damageproducing storms, it should be possible to envision a more rational program of coastal occupancy and development and to establish effective zoning and protective ordinances that have some basis in fact.

\footnotetext{
1 Also Department of Geography, University of Delaware.

2 The present article has resulted from a basic study of coastal occupancy and hazards, supported by the Office of Naval Research under Contract Nonr $4043(00)$. The study is being undertaken by C. W. Thornthwaite Associates, Laboratory of Climatology, with the assistance of research groups from the Geography Departments of Clark University and the University of Toronto.
}

The last two decades have witnessed a more rapid and extensive development of the Atlantic coastal margin than possibly any other comparable period in our history. This has resulted from the widespread development of a thin coastal area devoted primarily to seasonal occupancy for pleasure and recreation. The rising American standard of living and the lowering of work hours have given the average American more leisure time and income to devote to such recreation as boating, swimming, fishing, and other water-oriented activities. In many cases, such pursuits have led to the building or purchase of a second home situated as close as possible to the coastal margin and often used only for summer occupancy.

Builders, quick to recognize this desire for homes along the coast having harbors or waterways for boats and unobstructed views of the ocean, have dug miles of canals and inland waterways, leveled protective dunes, created marinas, and built homes as close to the water as possible. Few of these developments have been guided by even a cursory knowledge of coastal hazards and storms. Routine and common-sense protective measures have often been neglected, and in many cases, nature's own protection against the ravages of water and wind has been destroyed in an effort to produce a more salable property. A tremendous increase in damage to private property and to the shoreline itself has resulted from this increased occupancy of the coastal margin and the basic disregard of rational building and protective measures. The March 1962 storm merely pointed up the increasing seriousness of the problem and emphasized the need for an immediate solution. 


\section{Frequency of coastal storms}

Records of coastal storms and related damage during the past 42 years are contained in a number of different periodicals, newspapers, and weather summaries. As the method of reporting such storms, the reporting group, and the public interest have all changed, so also have the sources of data. The prime sources for all storm data during the period 1921-1962 have been U. S. Weather Bureau climatological publications. From 1921 until the end of 1949, brief records of severe storms were published in the Monthly Weather Review, while more detailed articles on storms of significance were included in the Review itself when warranted. From 1950 until the end of 1958, these storm records were included in the publication Climatological Data, National Summary. Since 1959 a much more expanded record of all severe storms has been published monthly in the special report entitled Storm Data.

In order to supplement these records, several other sources have been used for varying periods of time. Included among these are the Mariner's Weather Log, Weekly Weather and Crop Bulletin, Weatherwise, New York Times, and various articles in periodicals (e.g., Brown, 1939; Cooperman and Rosendal, 1963; Harris ${ }^{3}$; Simpson ${ }^{4}$; Thomas and Edelen, 1962; U. S. Weather Bureau $\left.^{5}\right)$. The record of hurricane damage over the past half century is particularly well documented (Ballenzweig, 1957; Cry et al., 1959; Howard, 1939; Mook, 1956; Harris, 1963; Carney and Hardy, 1962; Ludlam, 1963), but such storms constitute only about one-third of the total that has resulted in damage to the coastal areas.

The present study has been confined to the East Coast of the United States, from Florida to Maine. Storms affecting the Gulf of Mexico area, including the west coast of Florida, have not been included. Since this study was primarily interested in damage that resulted from the peculiar conditions existing at the sea coast (wave damage, coastal flooding, and tidal inundation), storms which caused damage by wind alone were not included.

Fig. 1 gives the yearly record of all storms that brought at least some water damage to part of the Atlantic coastal margin during the period 1921 to 1962. The record shows a marked increase in the number of damage-producing storms in the past two decades. From 1921 until the late 1930's, there was a fairly even distribution of coastal storms, averaging two to three a year. Actual numbers ranged from one in 1921, 1923,

${ }^{3}$ Harris, D. L., 1963 : Coastal flooding by the storm of March 5-7, 1962. U. S. Wea. Bur., manuscript, $22 \mathrm{pp}$.

4 Simpson, R. H., 1963: The unique development of the severe Atlantic coastal storm, March 1962. Paper presented at 211 Nat. Amer. Meteor. Soc. Meeting, New York, 11 pp.

5 U. S. Weather Bureau, 1963: Criteria for a standard project northeaster for New England north of Cape Cod. Memo. Hur. 8-5, Hydrometeor. Sec., Hydrol. Ser. Div., 91 pp.

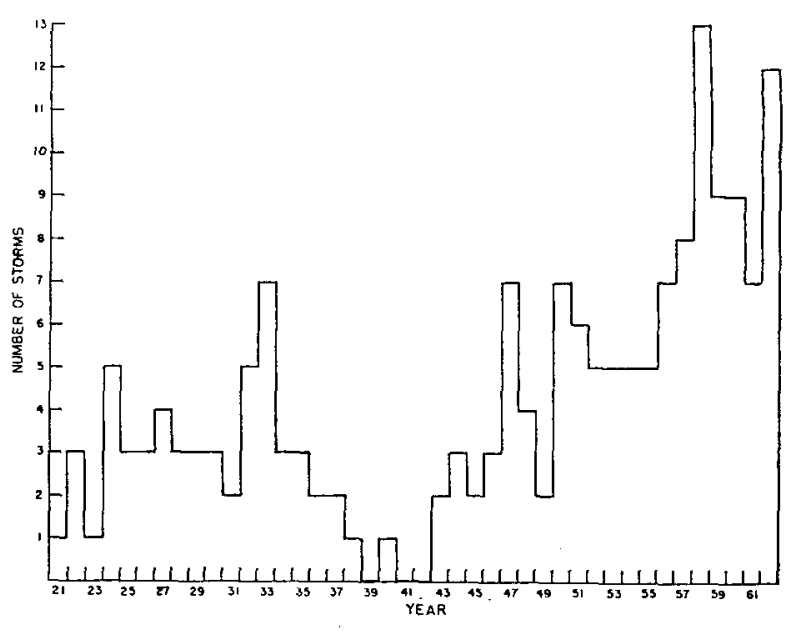

Frg. 1. Frequency of damaging coastal storms, eastern United States, 1921-1962.

and 1938 , to a maximum of seven in 1933. During the four years from 1939 through 1942, only one damageproducing coastal storm was reported in the sources studied.

During the 1940's the number of coastal storms increased from two in 1943 and 1945 to seven in 1947 and 1950. The average for this period is slightly higher than for the pre-1938 period, although the range of variation is consistent with the earlier period. Beginning in 1950, however, a new pattern of storm frequency has seemed to develop. During the past 13 years, the minimum number of yearly storms has been five (1952-1955), while the maximum numbers have been twelve in 1962 and thirteen in 1958. The average number of storms per year for this period has been over seven compared with two to three during the 1920's and 1930's. Because of the type of record which is available, it is not possible to say whether this pattern of storm frequency results only from random climatological variations. It is possible that the great increase in coastal occupancy and the resulting importance of damage-producing storms has led to a certain bias in reporting.

\section{Classification of storms affecting the coast}

Study of the daily synoptic charts for each of the 176 storms that occurred during the 1921-1962 period shows that certain weather situations recurred many times. One obvious meteorological situation frequently associated with coastal damage was the hurricane. It appeared possible to classify all listed coastal storms into one of eight different types on the basis of their origin, structure, and path of movement as follows:

1. Hurricanes and severe tropical storms.

2. Wave developments forming in the Atlantic Ocean well east of the United States mainland or in the vicinity of Cuba. 
3. Wave developments along cold or stationary fronts over the southeast coastal states or in the Atlantic Ocean just off the southeast coast.

4. Wave developments along cold or stationary fronts in the Gulf of Mexico forming west of $85 \mathrm{~W}$ longitude.

5. Depressions moving across the southern half of the United States that intensify upon reaching the Atlantic coast; no secondary development ahead of the storm center.

6. Depressions which develop as strong secondary cyclonic disturbances along the coast (often in the Hatteras area) ahead of a trailing wave or occluded center.

7. Intense cyclonic storms whose origin and entire path of movement are over land surfaces so that the low center remains west of the coastal margin.

8. Strong cold fronts accompanied by squall lines and severe local weather.

In addition, there were six storms with such diverse characteristics that they could not be grouped into any of the eight categories above. Since in each case the damage done by these storms was very small, they need not concern us further in the present study.

The above classes do not have sharp boundaries, and there are certain cases where storms fall near the border of divisions. Even within the classes, behavior of storms is variable; yet there seems to be sufficient consistency among the storms within a class and enough difference between classes to justify the present breakdown. In the present classification, the class 2 and 3 storms which form in the Atlantic are similar to Miller's (1946) type A cyclones, while the class 6 storms correspond to his type B cyclones. Austin (1941) has also discussed conditions which are favorable for cyclogenesis along the east coast. Both his situation 1 and situation 2 cyclogenesis conditions correspond with class 3 storms as listed here. Descriptions of the different classes as well as sample weather maps illustrating synoptic conditions during each major storm class follow.

1. The unique characteristics of hurricanes are well known. Hurricanes possess higher wind velocities than other storms that affect the East Coast. Their destructive power is great, although from the descriptive records of damage, hurricanes do not generally appear more severe than many class 2 storms. This is undoubtedly related to the more rapid movement of many hurricanes and to the relatively small diameter of the storms which result in shorter over-water fetch of the winds and, hence, less opportunity for wind-driven waves to pile up along the coast. During the period of record, 56 hurricanes brought damage to some part of the Atlantic coast. The synoptic charts of Fig. 2, showing the movement of hurricane Donna on three successive days in September 1960 along the East Coast of the United States, are fairly typical for storms in this class.
2. Storms of the second class include waves that develop into storms at some distance east or south of the continental United States in the Atlantic Ocean or in the vicinity of Cuba. With such late-forming depressions, the high pressure system north of the storm center has moved far enough eastward to block the northeasterly movement of the storm center. This results in very slow-moving depressions that often have a pronounced east-west elongation. This configuration of the isobars will, in turn, lead to a long over-water fetch of the winds and the build-up of significant wind-driven waves along the coast. As a result, this group is probably the most destructive of all of the storms that influence the coast. Fig. 3 is an example of an intense class 2 storm that occurred in January 1956. There were nine storms in this class during the 42-year period of record.

3 . Class 3 storms include waves that form over the southeastern coastal states or in the Atlantic Ocean fairly close to the coastal margin. These storms are also frequently blocked by high pressure systems pushing eastward north of the low center. Often a pronounced east-west orientation of the isobars results from the juxtaposition of the low center and the blocking high. In both the class 2 and 3 storms, the actual damage may result as much from the pressure gradient around the intense blocking high and the long east-west orientation due to the high as from the gradient around the low itself. Fig. 4 shows a portion of the synoptic charts for three days in November 1953 illustrating the development and movement of a class 3 storm. There were 23 storms in this class during the 42-year period of study.

4. Class 4 storms include depressions originating in the Gulf of Mexico west of $85 \mathrm{~W}$ longitude. These storms as well as class 3 storms originate as waves that often develop on the front marking the leading edge of a strong, cold mass of $\mathrm{cP}$ air moving southward from continental United States. The storms usually move eastward across Florida and often strengthen as they reach the Atlantic Ocean. Since they are seldom blocked, these storms generally move up the coast quite rapidly. Often they are pushed out to sea by the surge of high pressure which moves southeastward behind the storm center. Fig. 5 illustrates the development and movement of a typical class 4 storm during the period 12-14 February 1960. During the period of investigation there were 22 storms of this type that brought damage to the East Coast.

5. Class 5 storms are relatively few in number. The original cold front ahead of a mass of $\mathrm{cP}$ air moves eastward from the central part of the country and out into the Atlantic. Cyclogenesis occurs on the front before it reaches the coast. As the low center moves over the ocean, deepening occurs. The center then generally moves fairly rapidly eastward or northeastward. There were only 14 storms of this class which produced damage to the coastal areas during the 42-year period of record. Fig. 6 shows the pattern of development of a typical class 5 storm in January 1961. 

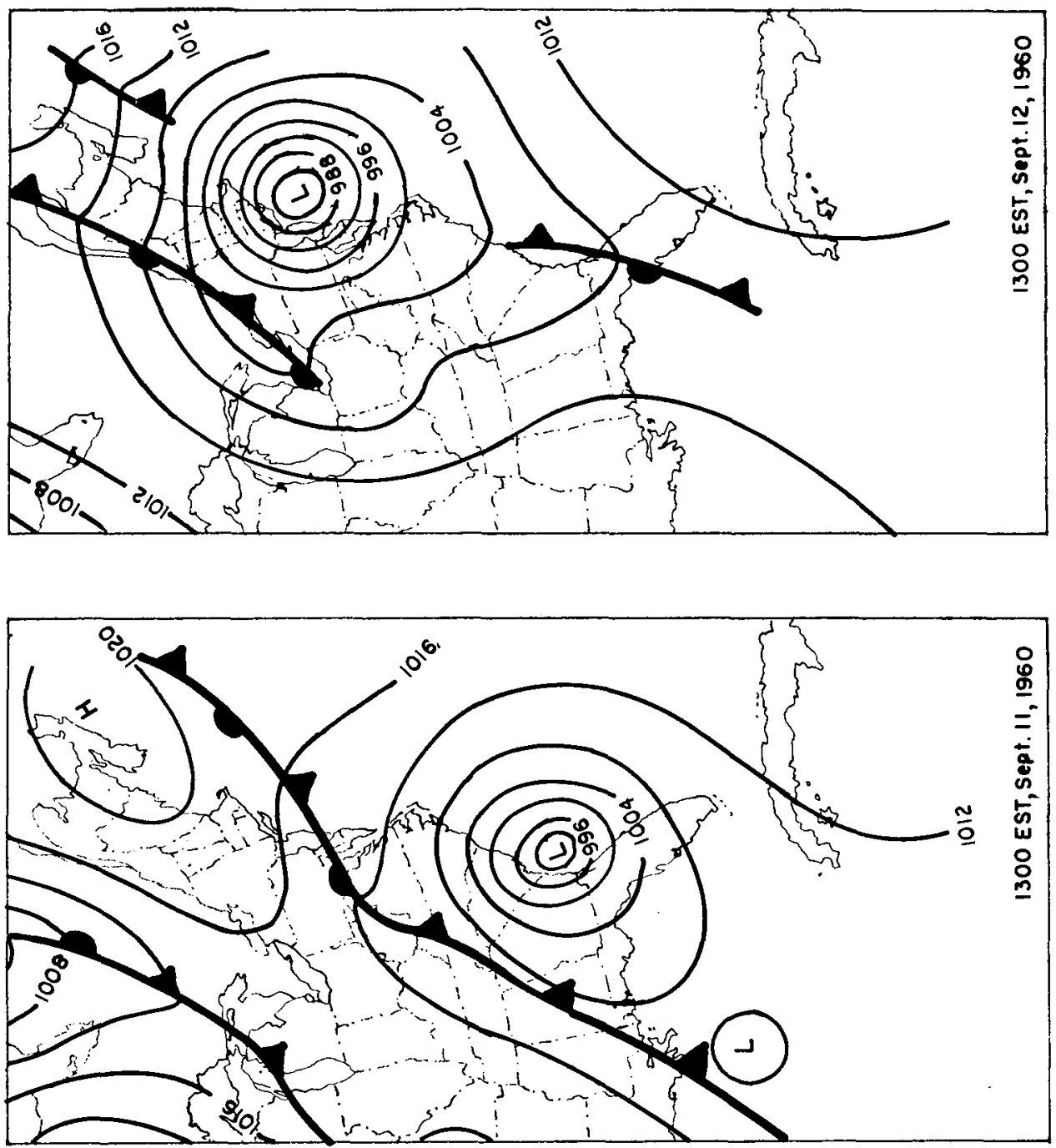

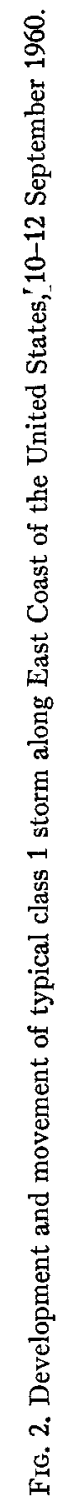

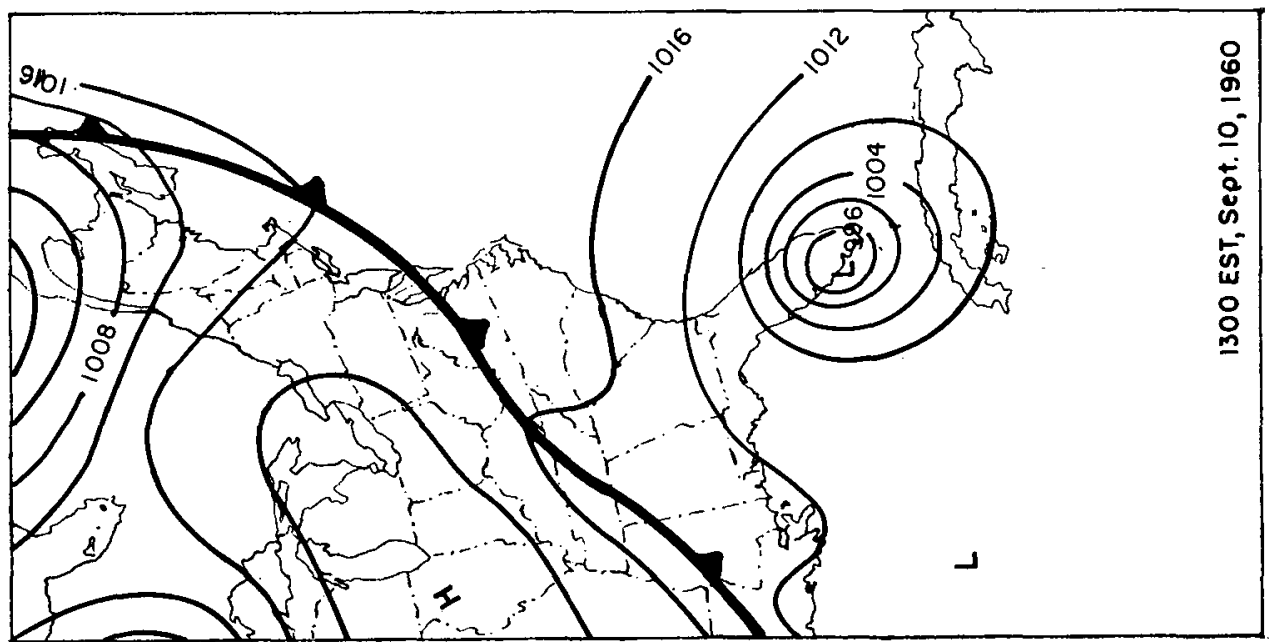




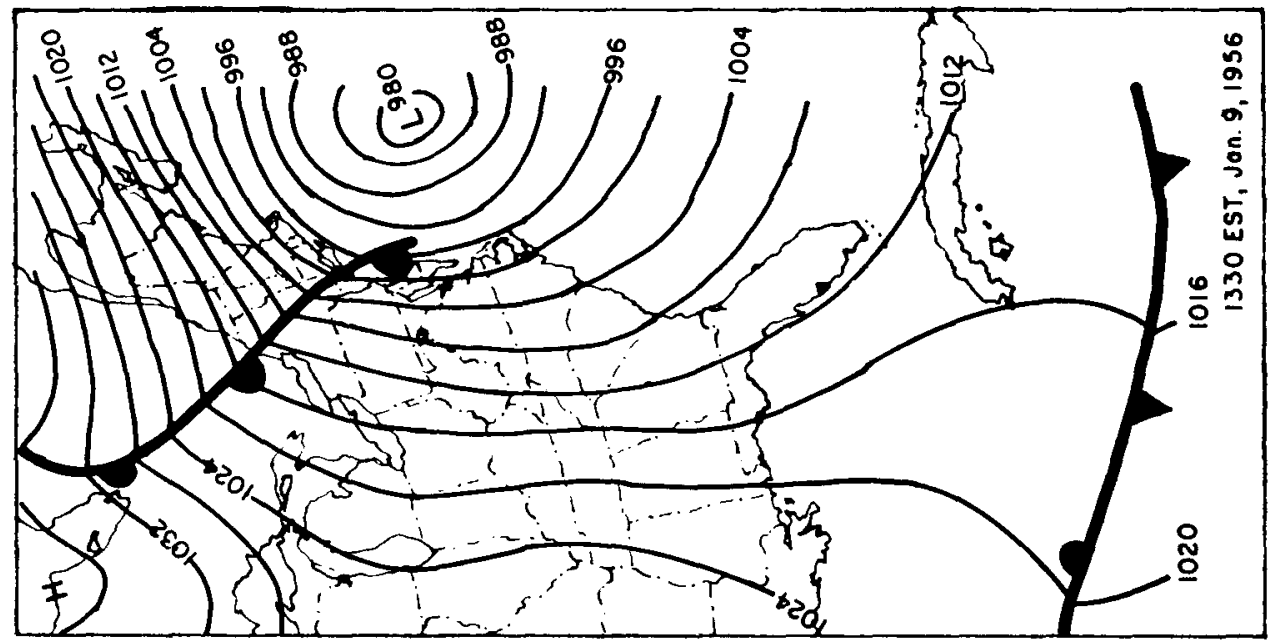

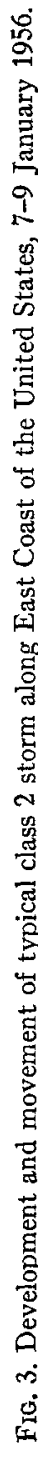
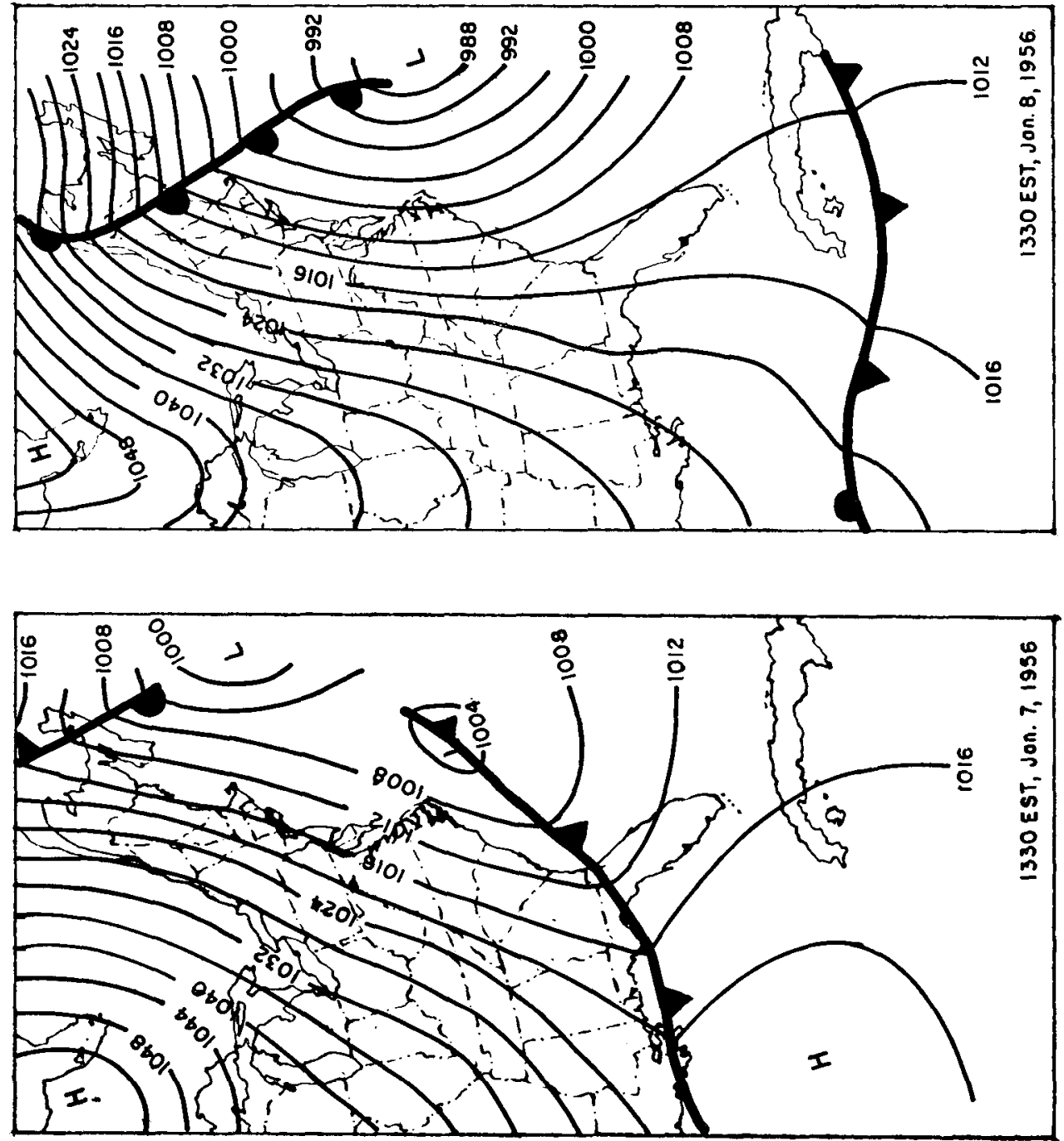


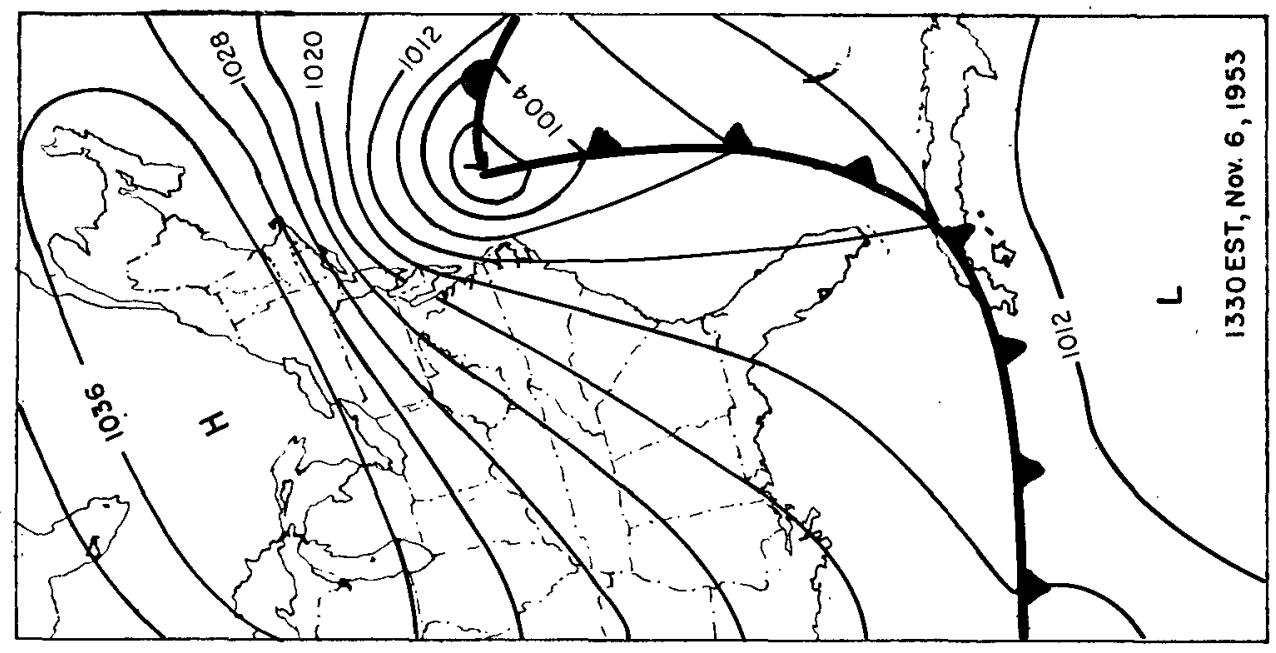

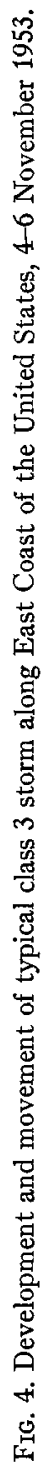

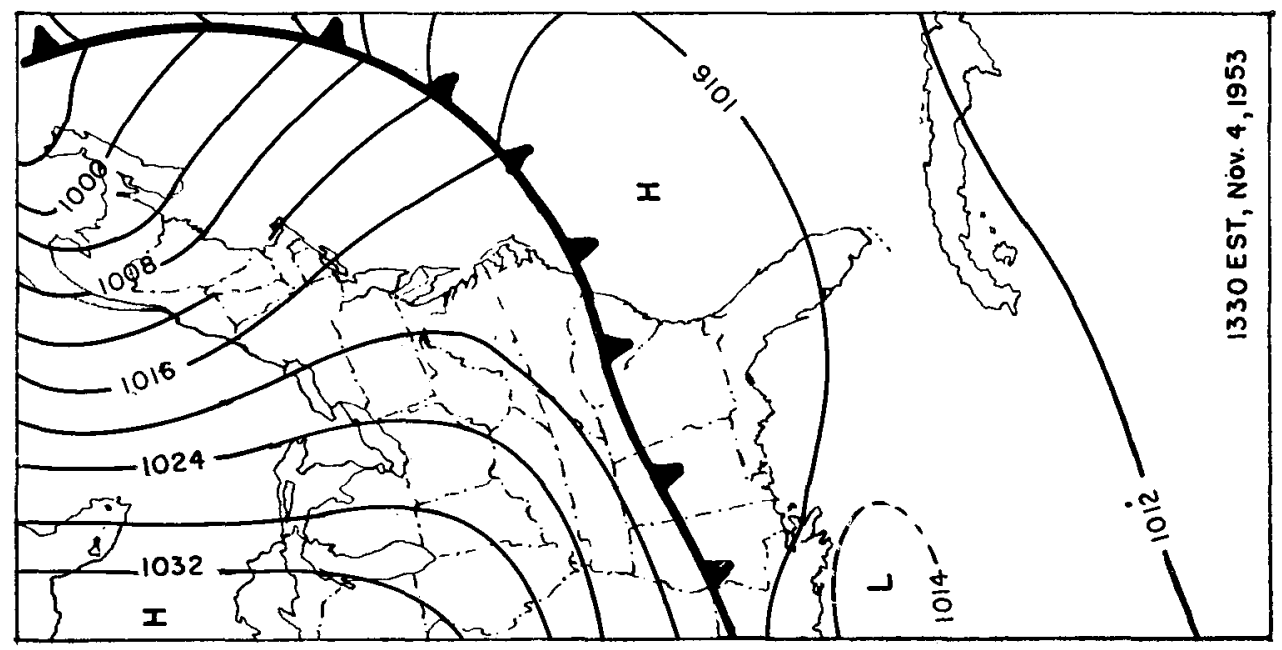




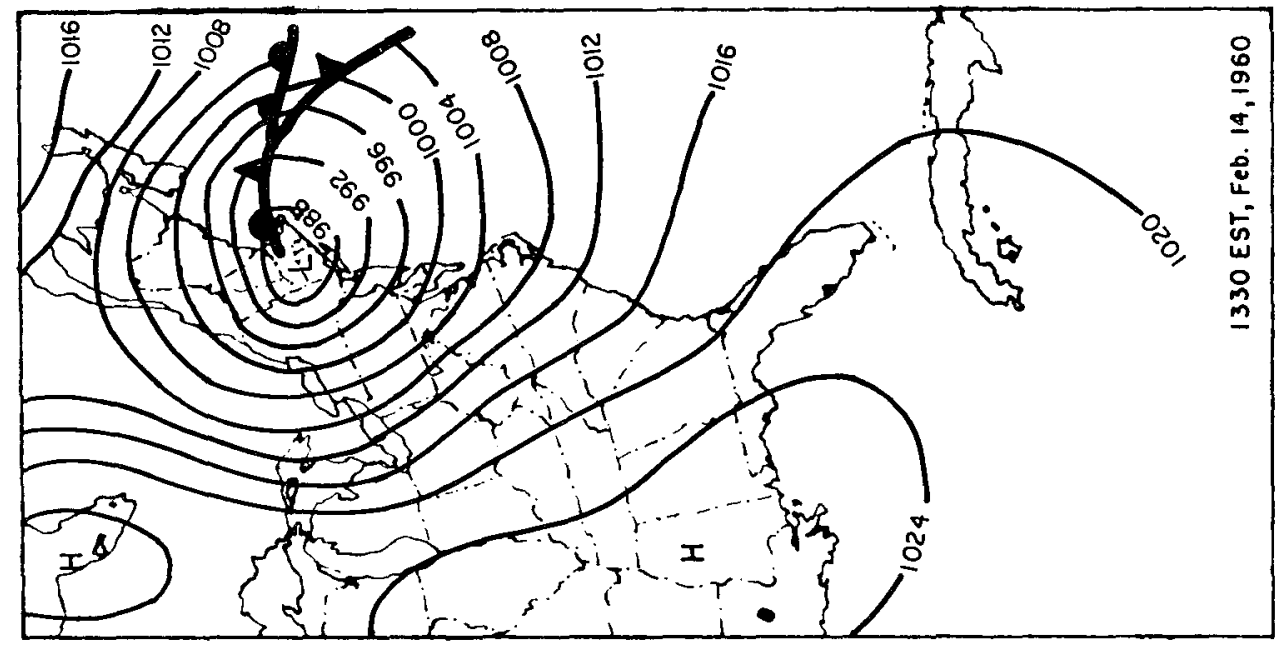

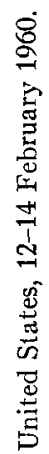
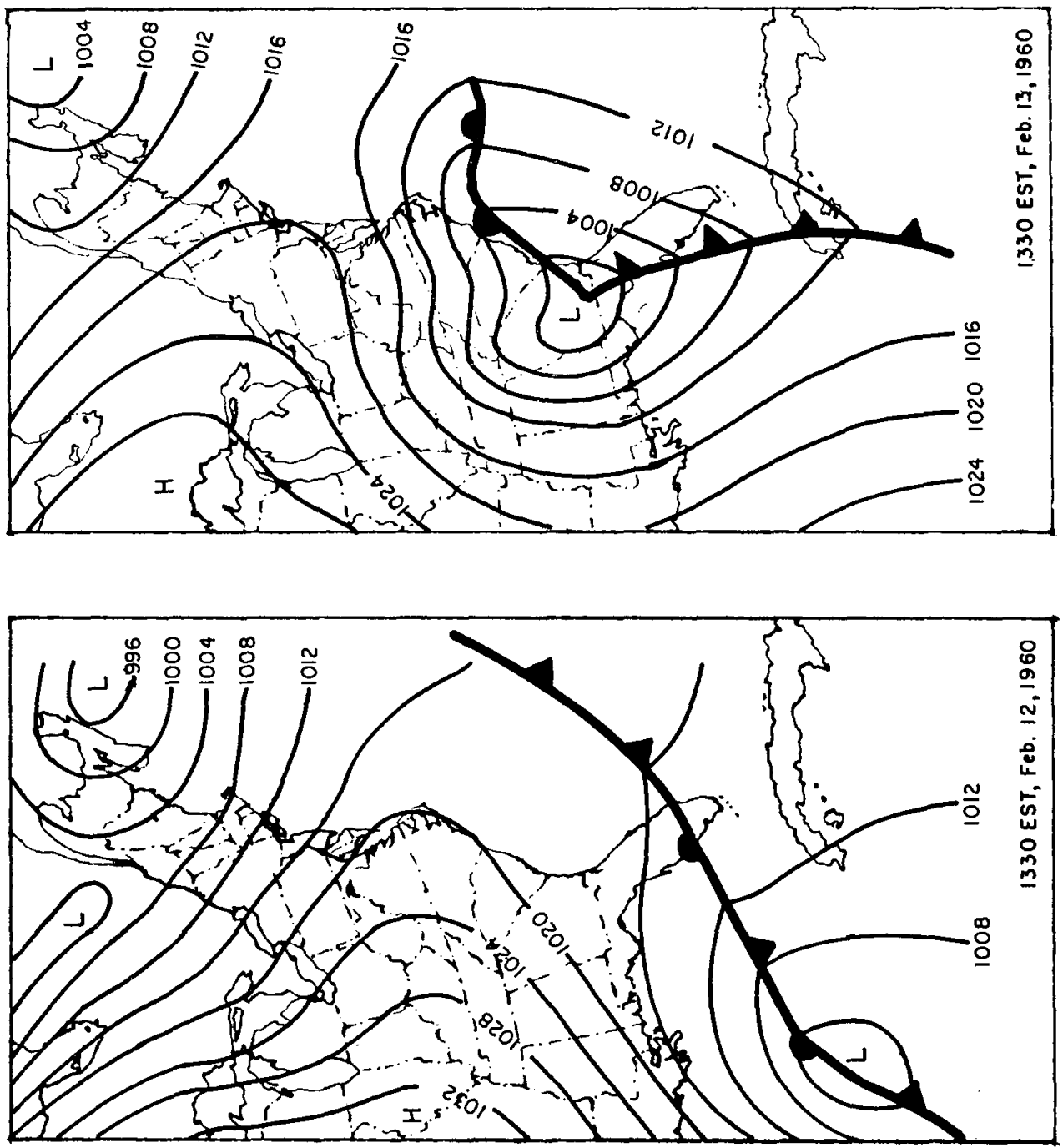

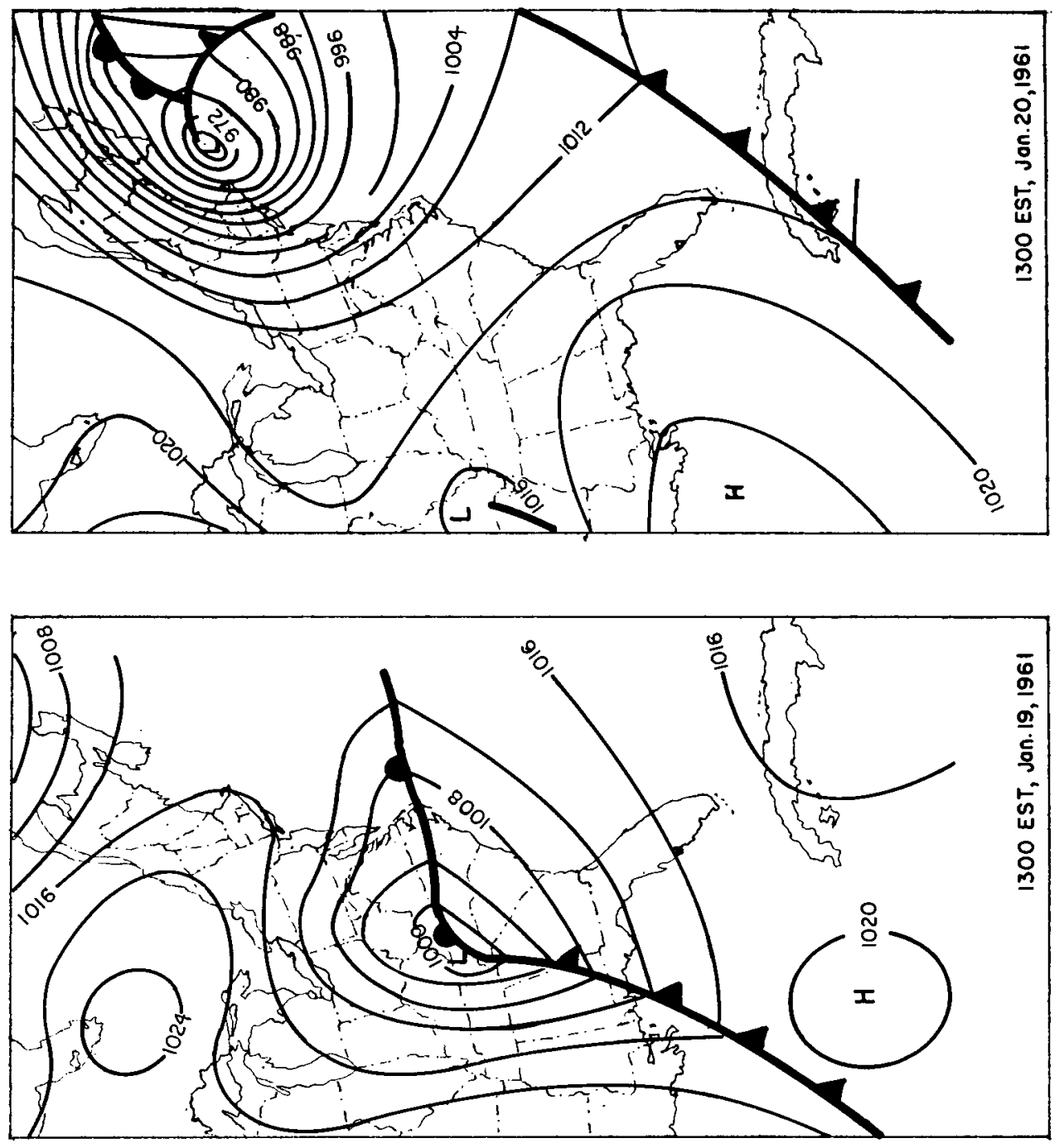

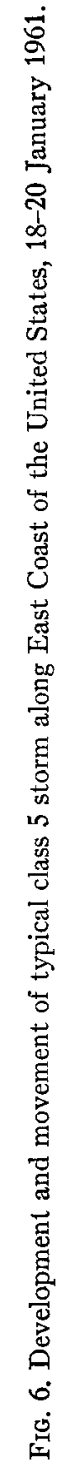




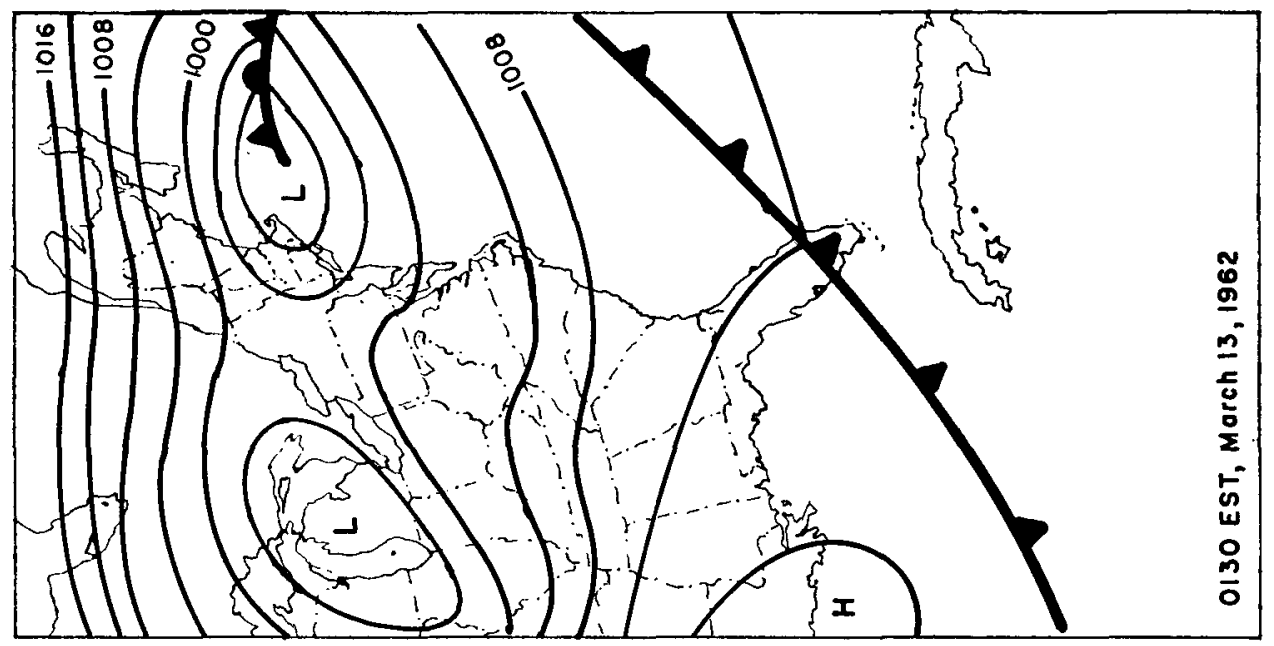

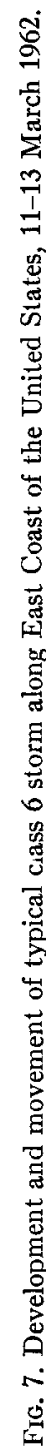
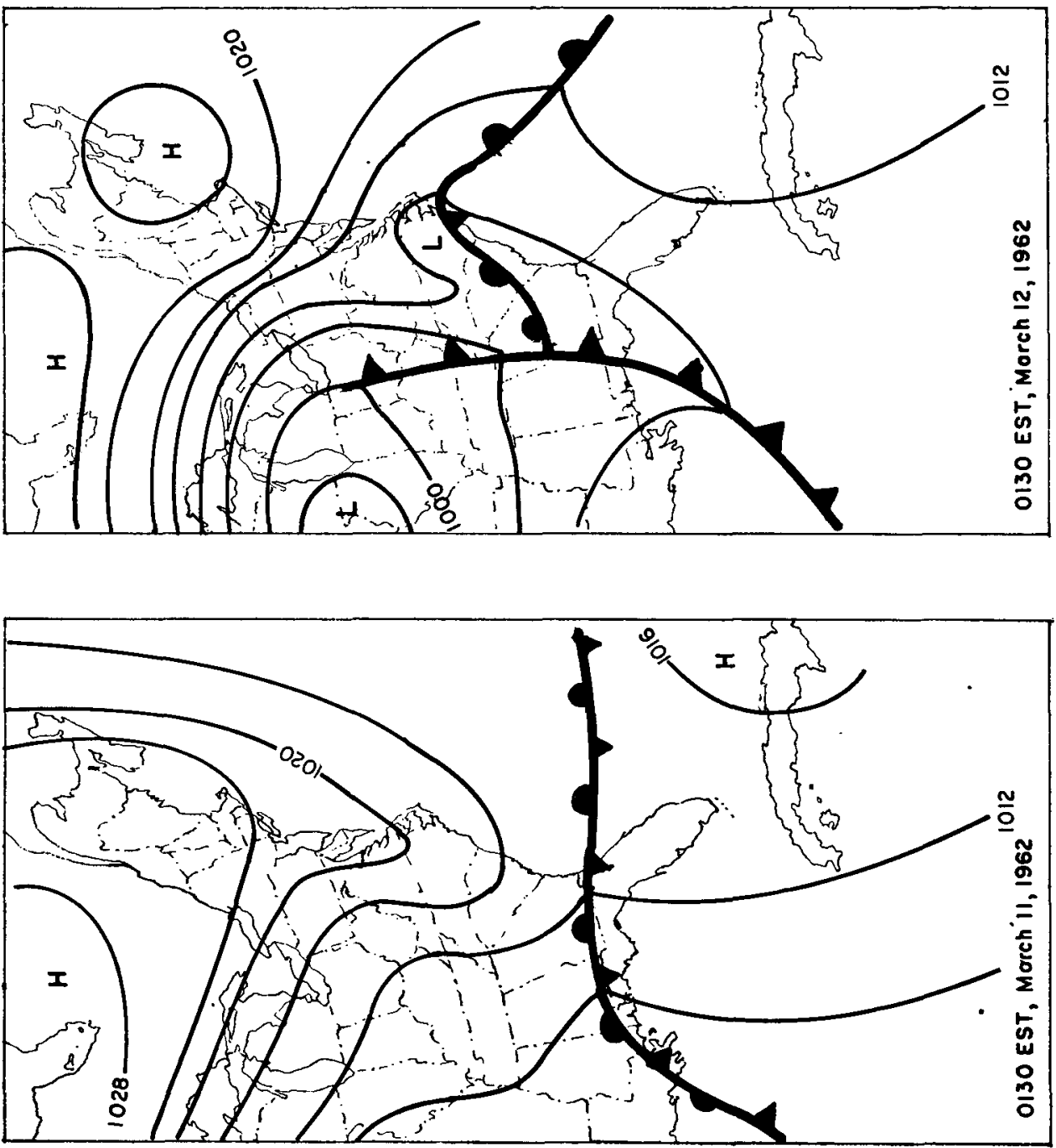

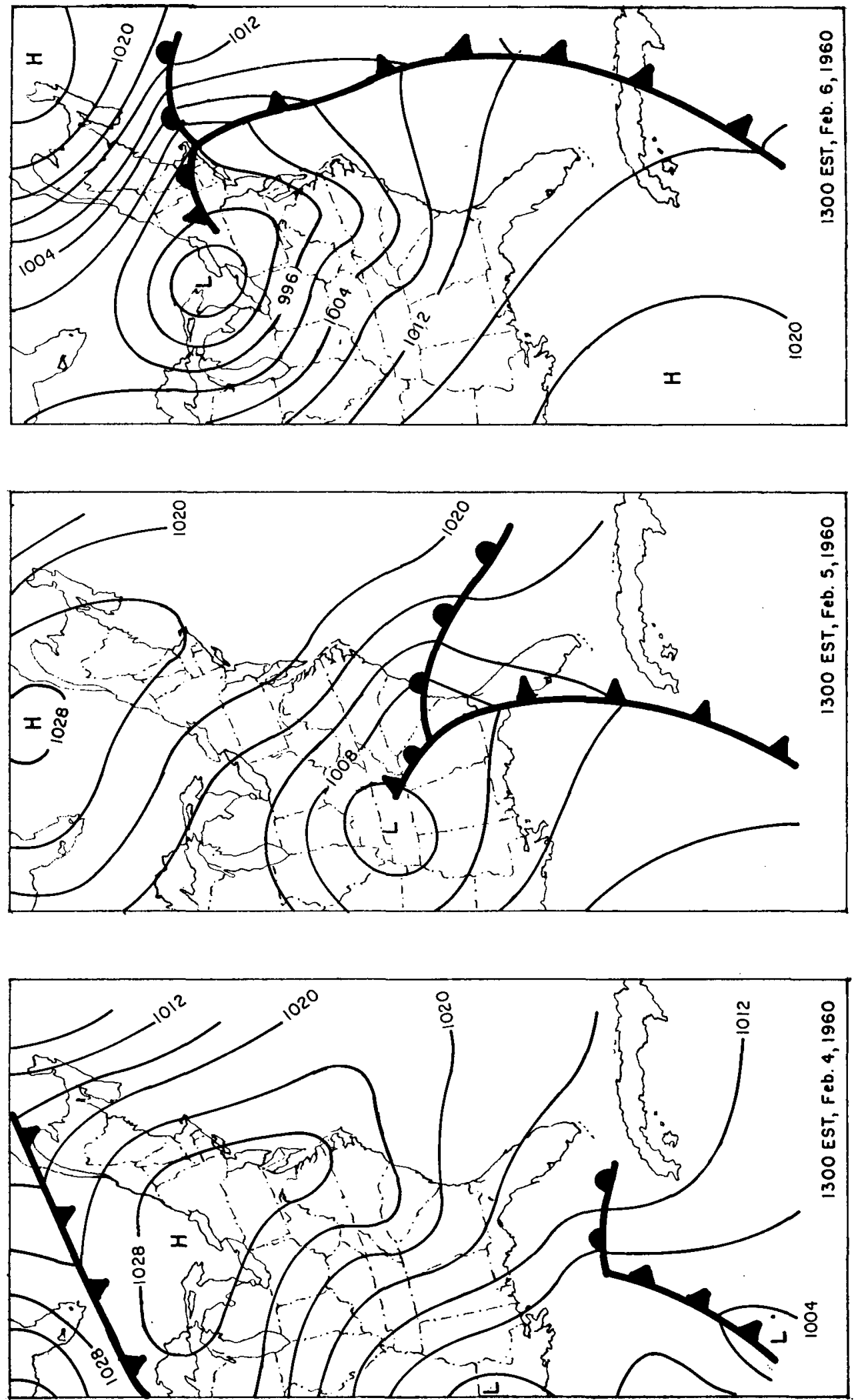
6. Class 6 storms are a more complex group. In general, cyclogenesis occurs in the vicinity of the coast on a warm or stationary front emanating from a parent cyclonic disturbance to the west. With the rapid development of the coastal secondary, often in the region of Cape Hatteras, the parent depression over the continental area fills and dissipates. Wave development over the coastal area can be most rapid, but generally the storm center moves rapidly northeastward so that damage is minimized. Fig. 7 is an example of a March 1962 storm in this class. Twenty-five storms of this type have resulted in damage to the coast since 1921.

7. Class 7 storms consist of disturbances which generally move northward over the Great Lakes and down the St. Lawrence River valley. These storms are usually highly developed and often move rapidly. Damage results when a strong pressure gradient develops between the storm center and a high pressure system to the east. There are 14 storms in this subcategory. Fig. 8 shows a typical example of the occurrence and development of one of these storms during the period 4-6 February 1960.

8. Class 8 storms consist mostly of severe local storms accompanying squall lines that are associated with strong cold fronts. There are no well developed cyclones associated with most of these storms and the damage produced is generally localized and relatively unimportant. There were seven storms in this class during the 42-year period of study.

Only rough estimates of damage from coastal storms are possible. In certain cases, broad ranges of dollar amounts of damage are available in published form. More usually, only general accounts of the storm and the resulting damage are available. From this information, it has been possible to divide estimated damage into three broad classes: low, moderate, and severe. Assigning 1 for low damage, 2 for moderate damage, and 3 for severe damage conditions, it is possible to obtain a rough estimate of the average severity of each of the foregoing classes of storms. Table 1 shows that class 2 storms are the most severe on the basis of this qualitative interpretation of the record, followed by class 3 ,

TABLE 1. Frequency and damage estimate by storm type, Atlantic coast, 1921-1962.

\begin{tabular}{ccc}
\hline Class of storm & Total number & Damage estimate* \\
\hline 1 & 56 & 2.05 \\
2 & 9 & 2.44 \\
3 & 23 & 2.09 \\
4 & 22 & 1.91 \\
5 & 14 & 1.69 \\
6 & 25 & 1.75 \\
7 & 14 & 1.54 \\
8 & 7 & 1.00
\end{tabular}

\footnotetext{
* Based on 1 for low damage, 2 for moderate damage, and 3 for
} severe damage. and class 1 storms. Class 8 storms resulted in the lowest amount of coastal damage.

Table 2 gives the seasonal frequency of storms of different types. The seasonal maximum of class 1 storms comes as expected in September, with a range of occurrence from June through November (except for one in February). Both class 2 and 3 storms are more frequent in the fall and early winter. While class 4 storms do occur in the fall and winter, the maximum of these storms occurs in March. Class 5 storms occur mainly from November through April, although two summer occurrences have been noted. Class 6 and 7 storms are also most frequent in the winter and early spring, while class 8 storms seem to favor the fall period, although the number of storms is so low that the distribution is not significant.

\section{Areal distribution of coastal storms}

In a hearing before the Congress following the storm of 5-8 March 1962, Simpson estimated that some portion of the Atlantic coast would experience damage from such a winter-type storm about once in four years. $\mathrm{He}$ further pointed out that there had been ten storms since 1900 which compared in severity to the 5-8 March 1962 storm. Any one locality on the coast might experience a storm of the severity of the March storm about once in 30 to once in 60 years (U. S. House of Representatives, 1962, p. 10).

These figures give the impression of a relatively infrequent occurrence of coastal storms. While there is the qualification that the figures apply to storms of like severity to the disastrous storm of March 1962, this is often overlooked or misunderstood. It would be useful to both coastal dwellers and builders to have information on the total number of storms that have produced some damage to the coast. At the same time, knowledge of the specific coastal areas subject to repeated damage would be desirable. It is, of course, important to know that once in every 30 years a very severe storm will bring extensive damage not only to a particular area but to the whole coastal margin. It may be of even greater significance, however, to know that an area has experienced 20 storms in 30 years that resulted in some

TABLE 2. Seasonal occurrence of storms by class.

\begin{tabular}{cccccccccccccc}
\hline \hline Type & J & F & M & A & M & J & J & A & S & O & N & D & Y \\
\hline 1 & & 1 & & & & 1 & 3 & 14 & 22 & 12 & 3 & & 56 \\
2 & 2 & & & & & & & 1 & & 2 & 3 & 1 & 9 \\
3 & 2 & & 2 & 1 & 1 & 1 & & 3 & 3 & 5 & 5 & & 23 \\
4 & 2 & 3 & 5 & 3 & 1 & & & & 2 & 2 & 2 & 2 & 22 \\
5 & 2 & 2 & 2 & 1 & & 1 & & 1 & & & 3 & 2 & 14 \\
6 & 2 & 4 & 3 & 5 & 1 & 1 & & & & 1 & 4 & 4 & 25 \\
7 & & 3 & 3 & 1 & & & & & & 3 & 2 & 2 & 14 \\
8 & 1 & - & - & - & 1 & & 1 & & 3 & 1 & & & 7 \\
Total & 11 & 13 & 15 & 11 & 4 & 4 & 4 & -19 & $\overline{30}$ & $\frac{26}{22}$ & $\overline{11}$ & $\frac{170}{170}$
\end{tabular}


damage to houses, streets, power lines, or commercial establishments. The individual who lives along the coastal margin may experience damage or loss from any of the 20 storms in 30 years. He will almost certainly experience some damage or loss from the once-inthirty-years storm. His overall chance of damage and loss is greater than once in 30 years because of the possibility that one or more of the smaller storms that result in only localized damage will also affect him particularly.

Table 3 lists by states the number of coastal storms resulting in some reported damage during the 1921-1962 period. The storms have been separated by class as well as geographically by state. The data show that the northern part of the coastal margin has experienced a considerably greater number of storms than the southern part. Coastal Massachusetts has experienced 78 damaging storms during this 42-year period, or nearly two per year, while New Jersey, Rhode Island, Maine, and Connecticut follow, in that order. On the other hand the coasts of Georgia, Delaware, and South Carolina have experienced the fewest damaging storms, less than once every other year. Florida, with its long coastline exposed to hurricanes and other tropical disturbances, has experienced slightly fewer storms than has New Hampshire, with only a short coast line in an area removed from the general hurricane track. The more exposed location of North Carolina is clearly revealed, since it experiences one damaging storm nearly every year in contrast to one damaging storm every two years and one every three years for South Carolina and Georgia, respectively. Of course, this pattern of distribution says nothing of the severity of the storms involved.

Table 4 includes a breakdown, by states, of the number of storms resulting in severe, moderate, and light damage that have affected the coast. This qualitative assessment of damage has again been made on the basis of available descriptions using 1 for storms of light damage, 2 for moderately severe storms, and 3 for severe storms. In this case, average severity does not vary greatly from state to state, ranging from 1.6 for Maine, Rhode Island, Connecticut, New Jersey, and Maryland, to 2.1 for Florida. There seems to be a tendency for the

TabLe 3. Number of damage-producing storms, by class and state, 1921-1962.

\begin{tabular}{|c|c|c|c|c|c|c|c|c|c|c|}
\hline State/Class & 1 & 2 & 3 & 4 & 5 & 6 & 7 & 8 & Total & $\begin{array}{l}\text { Storms } \\
\text { per year }\end{array}$ \\
\hline Maine & 8 & 5 & 7 & 12 & 6 & 5 & 6 & & 49 & 1.17 \\
\hline New Hampshire & 7 & 2 & 7 & 10 & 3 & 5 & 3 & & 37 & .88 \\
\hline Massachusetts & 20 & 4 & 11 & 14 & 7 & 14 & 5 & 3 & 78 & 1.86 \\
\hline Rhode Island & 11 & 1 & 9 & 9 & 6 & 12 & 3 & 1 & 52 & 1.24 \\
\hline Connecticut & 11 & 1 & 6 & 9 & 5 & 10 & 5 & 1 & 48 & 1.14 \\
\hline New York & 11 & 1 & 9 & 7 & 4 & 9 & 4 & & 45 & 1.05 \\
\hline New Jersey & 18 & 3 & 10 & 8 & 4 & 8 & 4 & 1 & 56 & 1.33 \\
\hline Delaware & 8 & 1 & 5 & 4 & 1 & 1 & & & 20 & .48 \\
\hline Maryland & 12 & $\hat{1}$ & 5 & 4 & 2 & 1 & & 2 & 27 & .64 \\
\hline Virginia & 19 & $\hat{1}$ & 7 & 7 & & 1 & & & 35 & .83 \\
\hline North Carolina & 23 & 3 & 5 & 7 & 2 & & & & 40 & .95 \\
\hline South Carolina & 14 & 1 & 3 & 2 & & 1 & & & 21 & .50 \\
\hline Georgia & 13 & & & 2 & & & & & 15 & .36 \\
\hline Florida & 23 & 5 & 4 & 2 & & & & & 34 & .81 \\
\hline
\end{tabular}

TABLE 4. Intensity of coastal storms and recurrence interval for storms bringing moderate and severe damage, by state, $1921-1962$.

\begin{tabular}{|c|c|c|c|c|c|}
\hline & Light & $\begin{array}{c}\text { Number of storms } \\
\text { Moderate }\end{array}$ & Severe & $\begin{array}{l}\text { Average* } \\
\text { severity }\end{array}$ & $\begin{array}{l}\text { Mean recurrence } \\
\text { interval (years) }\end{array}$ \\
\hline Maine & 23 & 21 & 5 & 1.6 & 1.6 \\
\hline New Hampshire & 15 & 18 & 4 & 1.7 & 1.9 \\
\hline Massachusetts & 26 & 42 & 10 & 1.8 & .8 \\
\hline Rhode Island & 24 & 23 & 5 & 1.6 & 1.5 \\
\hline Connecticut & 22 & 22 & 4 & 1.6 & 1.6 \\
\hline New York & 14 & 23 & 8 & 1.9 & 1.4 \\
\hline New Jersey & 25 & 26 & 5 & 1.6 & 1.4 \\
\hline Delaware & 6 & 13 & 1 & 1.8 & 3.0 \\
\hline Maryland & 12 & 14 & 1 & 1.6 & 2.8 \\
\hline Virginia & 11 & 20 & 4 & 1.8 & 1.8 \\
\hline North Carolina & 12 & 20 & 8 & 1.9 & 1.5 \\
\hline South Carolina & 6 & 12 & 3 & 1.9 & 2.8 \\
\hline Georgia & 5 & 10 & 0 & 1.7 & 4.2 \\
\hline Florida & 7 & 18 & 9 & 2.1 & 1.6 \\
\hline
\end{tabular}

* Based on 1 for light damage, 2 for moderate damage, and 3 for severe damage. 
southern states to be influenced by storms of greater severity, although the number of storms per state is generally greater for the northern part of the coast line than the southern.

The length of coastline exposed to damage from the sea varies considerably from 18 miles for New Hampshire to 399 miles for the east coast of Florida. ${ }^{6}$ In order to obtain the frequency of damage to any particular mile of coast line, one is not justified in dividing the number of storms by the miles of coast line, since all of the storms listed possessed a certain finite size and influenced a number of miles of the coast. Neither is one justified in using the value of storm frequency directly as an estimate of the recurrence interval for damaging storms in any state, since a small storm may bring damage to the whole New Hampshire, Delaware, or Maryland coast, while it may damage only a segment of the Florida or North Carolina coast. Assuming, however, that storms bringing moderate and severe damage are sufficiently large to result in some damage to the whole coastal margin of the state in which damage is listed, it is possible to obtain a rough estimate, by state, of the recurrence interval for damaging storms at any particular spot along the coastal margin. In the right-hand column of Table 4, the number of storms resulting in light damage to the coast has been removed from the total in each state, and the storm frequency for any particular spot along the coastal margin is given as the number of years between storms resulting in moderate to severe damage. These figures are related to the probability of damage for any particular spot on the coast.

The figures for frequency of damaging storms vary from one every 10 months ( 0.8 year) for Massachusetts to one every 4.2 years for Georgia. The recurrence interval given for the entire Massachusetts coast is undoubtedly shorter than is really experienced along any particular coastal reach. This is because the coast is so oriented that it presents two distinct areas for coastal damage. The south-facing shore from Buzzards Bay to Chatham on Cape Cod is exposed to all winds from southeast to southwest. At the same time such winds result in generally off-shore movement of water along the coast from Orleans on the northern side of Cape Cod to the New Hampshire border. Storms that affect the shore north and south of Boston and the north shore of Cape Cod have winds from the north and east. These would bring relatively little damage to the south shore of Cape Cod and Buzzards Bay. Thus, the orientation of the shore line has made part of the Massachusetts coast particularly susceptible to damage from storms with southerly winds and a different part of the coast

Figures are lengths of general outline of coast made with unit measure of 30 minutes of latitude on a $1: 1,200,000$ chart. Shore line of bays included to point where they narrow to width of unit measure. Distance across at that point is inciuded. (Source: U. S. Coast and Geodetic Survey.) susceptible to storms with northeasterly winds. This has resulted in essentially twice as many damaging storms as other states. Actually, the chance of coastal damage in Massachusetts is not much greater than in Rhode Island or New Hampshire. Separating the storm figures for Massachusetts into those affecting the southward-facing shore and those affecting the eastwardfacing shore, the values of recurrence interval approximate closely the figures of 1.5 years for Rhode Island and 1.9 years for New Hampshire. An average value of 1.6 to 1.7 years is reasonable for any particular point on the Massachusetts shore line. The value of storm recurrence for North Carolina is similarly influenced by the particular exposure of the coast line.

\section{Summary and conclusions}

Study of the storms which have brought damage to the East Coast of the United States over the past 42 years has revealed that eight general synoptic situations result in essentially all of the damage-producing situations. These include hurricanes, wave developments well east in the Atlantic Ocean or in the vicinity of Cuba, wave developments over Florida or the nearby Atlantic coastal waters, wave developments in the central and western Gulf of Mexico, depressions that move across southeastern United States and intensify upon reaching the Atlantic coast, secondary cyclonic disturbances forming in the Hatteras area ahead of trailing waves or occluded centers, intense depressions moving northeastward, west of the coastal margin, and severe local storms associated with squall lines. From descriptions of the damage produced by these storms, it appears that the most severe damage has resulted from wave developments on frontal surfaces in the Atlantic Ocean and from hurricanes. The southern states have experienced a smaller number of storms than the northern states, although the severity of storms seems to be greater for the southern states. Storms of moderate to severe intensity might be expected at any place along the east coast of the United States on an average of once every 1.4 years in New York and New Jersey, the area of most frequent occurrence, to once every 3.0 and 4.2 years in Delaware and Georgia, the areas of least frequent occurrence.

The study has so far been limited by the fact that it has not been possible to define quantitatively the severity and extent of various coastal storms; nor is it yet possible to compare the strength of damage potential of recent storms with those that occurred many years ago. Dollar amounts of damage are not sufficient criteria for such comparisons nor are descriptions of storms from newspaper or periodical accounts. What is still needed is a way to characterize the intensity of a storm based upon such readily measurable parameters as wind gradient, central pressure, fetch of the wind, and relation to apogean, perigean, spring, and neap 
tides so that a physical or climatic rather than an economic or human evaluation of severity is obtained.

The physical nature of the coast itself has not been considered in this study. Certain areas of the coast are particularly susceptible to storm damage, while other areas are not prone to flooding or tidal inundation during even the most severe coastal storms. The characterization of frequency of storm damage by whole states masks the real likelihood of damage, especially in those areas where the coast is naturally protected against storms. Because of this, the figures of the frequency of damaging storms probably err on the pessimistic side, even though storms of light damage have been eliminated. Certainly, there will be portions of the coast that experience storms less frequently than the figures indicate.

Damage from coastal storms will undoubtedly increase significantly in the years to come as development of the coastal area proceeds. It is vital that we begin now to understand all aspects of the coastal storm problem if we are to develop the most rational program. of adjustment to this part of our natural environment. The present study into the climatology of coastal storms is only one of a large number of human, economic, cultural, and physical studies that are needed as we seek the wisest possible use of our coastal resource at lowest cost to our national economy.

\section{REFERENCES}

Austin, J. M., 1941: Favorable conditions for cyclogenesis near the Atlantic coast. Bull. Amer. meteor. Soc., 22, 270.

Ballenzweig, E. M., 1957: Fluctuations in frequency of tropical storms. Weatherwise, 10, 121-125.

Brown, C. W., 1939: Hurricanes and shore-line changes in Rhode Island. Geogr. Rev., 29, 416-430.

Carney, C. B., and A. V. Hardy, 1962 : North Carolina hurricanes. U. S. Wea. Bur., 26 pp.

Cooperman, A. I., and H. E. Rosendal, 1963: Mean five-day pressure pattern of the great Atlantic coast storm, March 1962. Mon. Wea. Rev., 91, 337-344.

Cry, G. W., W. H. Haggard, and H. S. White, 1959: North Atlantic tropical cyclones. Tech. Paper 36, U. S. Wea. Bur., $214 \mathrm{pp}$.

Harris, D. L., 1963 : Characteristics of the hurricane storm surge. Tech. Paper 48, U. S. Wea. Bur., 139 pp.

Howard, A. D., 1939: Hurricane modification of the offshore bar of Long Island, New York. Geogr. Rev., 29, 400-415.

Ludlam, D. M., 1963: Early American hurricanes, 1492-1870. The history of American weather, No. 1, Boston, Amer. Meteor. Soc., 198 pp.

Miller, J. E., 1946: Cyclogenesis in the Atlantic coastal region of the United States. J. Meteor., 3, 31-44.

Mook, C. P., 1956: Hurricanes entering U. S. mainland-Eastport to Hatteras, 1635-1955. Weatherwise, 9, 125.

Thomas, D. M., and G. W. Edelen, Jr., 1962: Tidal floods, Atlantic City and vicinity, New Jersey. Hydrologic Investigations, Atlas HA-65, U. S. Geol. Sur.

U. S. House of Representatives, 1962: Improvement of storm forecasting procedures. Hearing before subcommittee on oceanography, Merchant Marine and Fisheries, 87th Congress, $111 \mathrm{pp}$. 